STUDI

FRANCESI

\section{Studi Francesi}

Rivista quadrimestrale fondata da Franco Simone

185 (LXII | II) | 2018

OCTAVE MIRBEAU: UNE CONSCIENCE AU TOURNANT

DU SIEECLE - sous la direction de Ida Merello

\title{
MARIE GABORIAUD, Une vie de gloire et de souffrance. Le mythe de Beethoven sous la Troisième République
}

\section{Ida Merello}

\section{(2) OpenEdition}

1 Journals

\section{Edizione digitale}

URL: https://journals.openedition.org/studifrancesi/13865

DOI: $10.4000 /$ studifrancesi. 13865

ISSN: 2421-5856

\section{Editore}

Rosenberg \& Sellier

\section{Edizione cartacea}

Data di pubblicazione: 1 août 2018

Paginazione: 345

ISSN: 0039-2944

\section{Notizia bibliografica digitale}

Ida Merello, «MARIE GABORIAUD, Une vie de gloire et de souffrance. Le mythe de Beethoven sous la Troisième République», Studi Francesi [Online], 185 (LXII | II) | 2018, online dal 01 août 2018, consultato il 15 novembre 2021. URL: http://journals.openedition.org/studifrancesi/13865 ; DOI: https://doi.org/ 10.4000/studifrancesi. 13865

Questo documento è stato generato automaticamente il 15 novembre 2021.

\section{(c) (1)}

Studi Francesi è distribuita con Licenza Creative Commons Attribuzione - Non commerciale - Non opere derivate 4.0 Internazionale. 


\title{
MARIE GABORIAUD, Une vie de gloire et de souffrance. Le mythe de Beethoven sous la Troisième République
}

\author{
Ida Merello
}

\section{NOTIZIA}

MARIE GABORIAUD, Une vie de gloire et de souffrance. Le mythe de Beethoven sous la Troisième République, Paris, Classiques Garnier 2017, 606 pp.

1 Frutto di un lungo lavoro di dottorato, il saggio si segnala per ricchezza e sfumatura di analisi, e padroneggia con grande disinvoltura non solo la critica letteraria francotedesca, ma anche quella musicale. È al punto di incontro tra letteratura e musica, infatti, che è studiata l'evoluzione del mito di Beethoven nel periodo della Terza Repubblica, con uno sguardo indietro fino a inizio Ottocento. L'A. sottolinea l'eterogeneità dei discorsi su Beethoven, da parte di musicologi, di letterati incaricati della rubrica musicale sulle riviste e i quotidiani, e di scrittori appassionati di musica. La critica tecnica era infatti affiancata da quella impressionistica di chi non conosce il linguaggio musicale, e da scrittori che pur conoscendolo preferivano lasciare spazio alle impressioni personali. Nello sviluppo del discorso sul mito beethoveniano, l'A. si sofferma in particolare su Jacques Rivière (di cui confronta la critica con quella di Boris de Schloezer), Gide, Claudel e naturalmente Rolland. Cerca quindi di distinguere le diverse "cellule" mitiche, sottolineando l'importanza della Société des Concerts du Conservatoire de Habeneck per la diffusione dell'opera di Beethoven tra il 1828, data di fondazione, e il 1870, riconoscendo altresì il ruolo fondamentale di Hoffmann, che proprio nel 1828 si afferma con prepotenza in Francia grazie alla traduzione delle sue opere. È così che si passa dalla visione di un musicista bizzarro dagli accordi "barbares" di inizio secolo a quella di caposaldo del romanticismo spiritualista tedesco, e a questo proposito l'importanza delle traduzioni delle monografie tedesche è opportunamente 
segnalata. Dopo la scomparsa della generazione contemporanea a Beethoven, si assiste a un rinnovamento del mito, che l'A. vede coincidere con l'avvento della Terza Repubblica. Annesso dal nazionalismo tedesco tramite Wagner, Beethoven entusiasma ugualmente i Francesi come spirito ribelle e rivoluzionario. L'A. si discosta dall'abitudine critica di considerare Rolland il fondatore del mito francese, per evidenziare il carattere soggettivo della sua monografia e inserirla in un contesto più ampio, dove trovano ampio spazio anche i «Cahiers de la Quinzaine» di Péguy. Beethoven è per tutti l'eroe dell'antimaterialismo: anche se al volgere del secolo non è più un riferimento per le avanguardie, conserva la modernità eterna del mito e svolge un ruolo messianico come eroe virile della coscienza moderna. 